\title{
Assessing the changes of the landmass surrounded by the Indian coast
}

\author{
Sridhara Nayak \\ Centre for Oceans, Rivers, Atmosphere and Land Sciences, \\ Indian Institute of Technology Kharagpur, India
}

\begin{abstract}
This study explores the changes in the landmass bounded by the coast of India during 1975-2005 by using on-screen visual interpretation technique (with $100 \mathrm{~m}$ resolution and 1:50,000 scale) from NASA Landsat Imagery in three different time periods viz. 1975, 1990, and 2005. The result indicated an overall expansion of $130 \mathrm{sq} . \mathrm{km}$ area of the landmass that surrounded by the Indian coast during 1975-2005 (74 sq. km during 1975-1990 and 56 sq. km during 1991-2005). These estimations are based on the preliminary analysis and may be estimated more accurately by reducing the scale and using further higher resolution images.
\end{abstract}

Key words Landmass expansion, India Coast, Landsat Images

Author's present address:

Disaster Prevention Research Institute, Kyoto University, Kyoto, Japan Email: nayak.sridhara.2n@kyoto-u.ac.jp

\section{Introduction}

It is well recognized that the landmass and coastal region are changing in many places around the world (Kunte and Wagle, 2005; Webb and Kench, 2010; Australia Network News, 2010; BBC News, 2010; Nayak et al., 2013; Nayak and Mandal, 2019a). Kunte and Wagle (2005) documented an increase of 30-35 km towards the sea along eastern coast of India since the Holocene period. Jayappa et al. (2003) surveyed eight beaches in Dakshina Kannada and Udupi districts of India to understand morphological changes in the coast due to erosion and sediment deposition. Their study indicated that the shoreline has protruded by about $225 \mathrm{~m}$ on up-drift side and retreated by $165 \mathrm{~m}$ on down-drift side between December 1993 and July 1995. Mergner and Scheer (1974) reported a significant rise in corals along the coast of India. An expansion in the low lying Pacific Islands is also highlighted in Webb and Kench (2010), which were mostly due to the atoll reef platforms, dynamic landform. Australia Network News (2010) and BBC News (2010) reported that $80 \%$ of the Pacific islands mostly either unchanged or expanded and some expanded by 20-30\%. 
Soil erosion plays major role for sediment formation and run off plays major role for transportation of sediments (Narayanna and Babu, 1983; Manjunatha and Shankar, 1992; Thanh et al., 2004; Kunte and Wagle, 2005; Mettier et al., 2008; Li et al., 2011). Thus if sediment deposits along the coastline for years and years, it results expansion of the coastal landmass. In a study, Narayanna and Babu (1983) highlighted that India has lost $\sim 29 \%$ of its total eroded soil into the sea and the rivers plays the major rule for the discharge of sediments into the sea. Chandramohan et al. (2001) documented an annual discharge of nearly $1.2 \times 10^{12}$ kilograms of sediments into the coast of India. Manjunatha and Shankar (1992) reported sedimentation rates at 0.72 and $0.56 \mathrm{~mm} / \mathrm{yr}$ in 2 cores along continental shelf of western India. All these studies indicated an expansion in Indian coastal landmass.

However, the changes in Indian landmass is so far not well documented in previous researches. In a recent study, Nayak and Mandal (2019a) investigated the morphological changes along the coast of India 1975-2005, but they did not discuss enough about the Indian landmass during 1975-2005. In this study, the work of Nayak and Mandal (2019a) is extended and the changes in the area of the landmass that surrounded by the Indian coast during 1975-2005 are explored through two periods viz. 1975-1990 and 1991-2005. Section 2 presents the study area, data and methods are presented. Section 3 presents the results and discussions of this study. The conclusions drawn from the study are given in the last section.

\section{Methodology and Data used}

This study focused on the Indian landmass that lies on the Indian Plate and bounded by the Arabian Sea, Bay of Bengal and Indian Ocean (Figure 1). The geometrically corrected three bands (4, 3 and 2) of Landsat MSS data are used for the year 1975 and three bands (7, 4 and 2) of Landsat TM and $\mathrm{ETM}^{+}$data are used for the years 1990 and 2005 respectively. These datasets are the National Aeronautics and Space Administration (NASA) satellite based and available in about $185 \mathrm{~km} \times 185$ $\mathrm{km}$ slab formats at the Global Land Cover Facility (GLCF). The scenarios over the study region for the years 1975, 1990, and 2005 were created by using about 95 slabs for each year. Due to nonavailability of the slabs over the whole region in the same year, the scenes of the adjacent years were used to obtain the landmass scenario.

The geometrically rectified bands were combined together by the process of layer stacking and mosaicking using ERDAS Imagine to find the whole study region as a single image for each year 
viz. 1975, 1990, and 2005 (Figure 2). The onscreen digitization method in ArcGIS software was used to calculate the area of the landmass surrounded by the Indian coast. This method is generally known as on-screen visualization technics. Multitude of studies (e.g., Nayak and Behera, 2008) have used

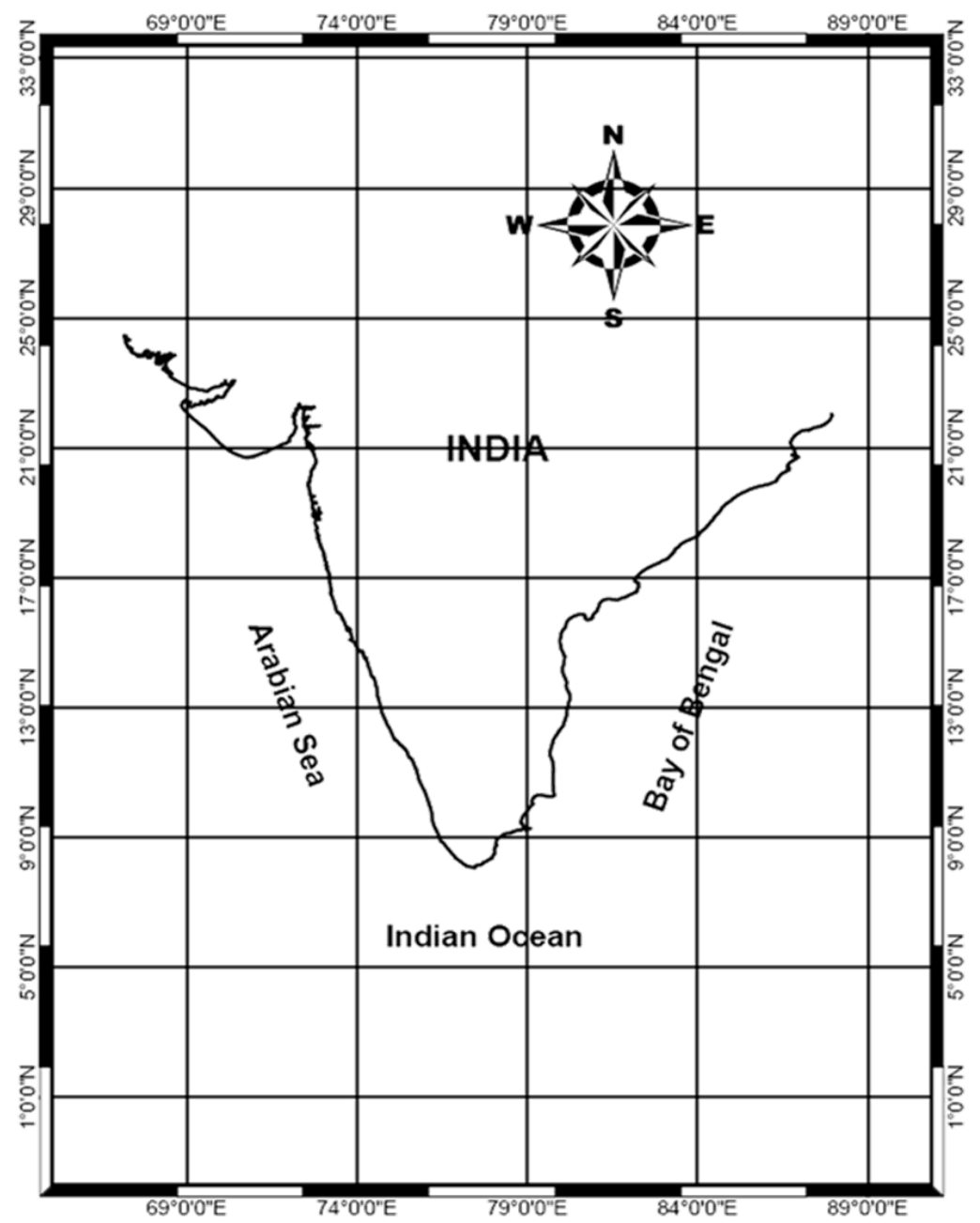

Figure 1: The location map of the study region, the landmass that surrounded by Indian coast.

this technique over various regions. In the present study. the regions with blue and black tones, visible as smooth texture and contiguous pattern in the image are considered as sea. During the digitization, few Islands are noticed far away from the Indian coast. Such Islands are excluded in this study. The image resolution and the scale are kept as 100 meter and 1:50,000 respectively for each year. Finally, the total area of the whole study region (Figure 1) for each year were estimated separately. 


\section{Results and Discussions}

The entire area of the landmass bounded by the coast of India coast for the years 1975, 1990, and 2005 are shown in the Figure 2. The figure $2 a, 2 b$, and $2 c$ show the area of the study region for the year 1975, 1990, and 2005 respectively. The total areas of the study region in 1975, 1990, and 2005 are calculated and given in Table 1. It shows that the total areas of the landmass of the study region in 1975,1990 , and 2005 are 1,593,923 sq. km, 1,593,997 sq. km, and 1,594,053 sq. km respectively. The area of the study region for each year does not show much differences because of the large area and small variations. It is noticed that the landmass that surrounded by Indian coast is expanded by 74 sq. $\mathrm{km}$ in first fifteen years i.e. during 1975-1990 and it is further expanded by $56 \mathrm{sq}$. km in next fifteen years i.e. during 1990-2005. This indicated an overall expansion of 130 sq. km area of landmass during 1975-2005. These estimates may be associated with some errors because of the resolution and scale selected in the study. Thus usage of further higher resolution images and further reduction of scale can reproduce more accurate results. However, the comparative analysis with literatures indicates that such expansions are plausible and could be due to the deposition of sediments along the coast of India. Similar features are noticed over few regions along Indian coast and some of them are shown in the figure 3. Figure 3a-c showed that the eroded soils are deposited in the sea beaches and resulted expansion of the landmass to some extent. Similarly Figure 3d-f showed the escaped surface matters are deposited to the beaches and resulted expansion of the landmass.

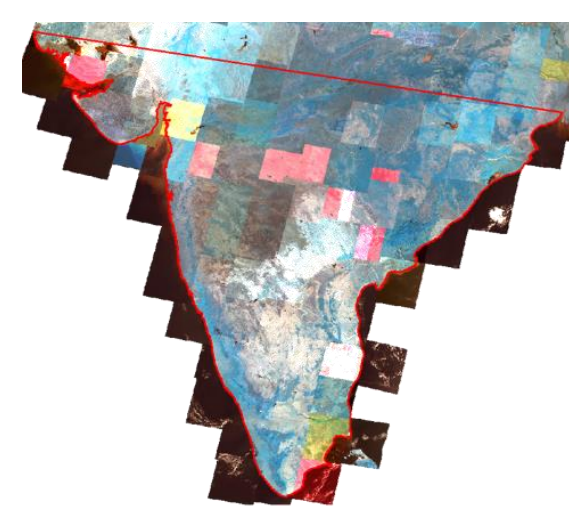

(a) 1975

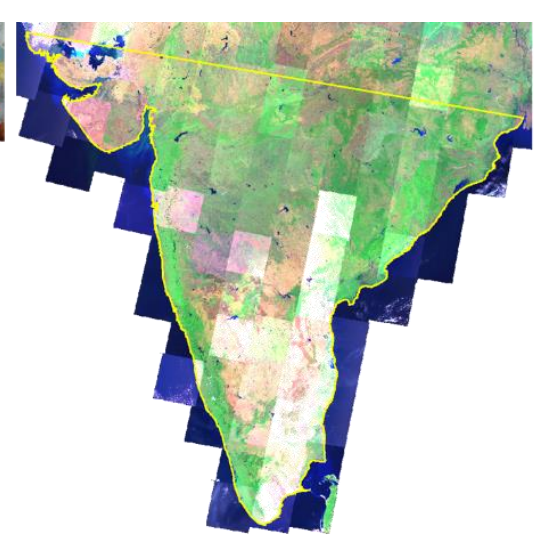

(b) 1990

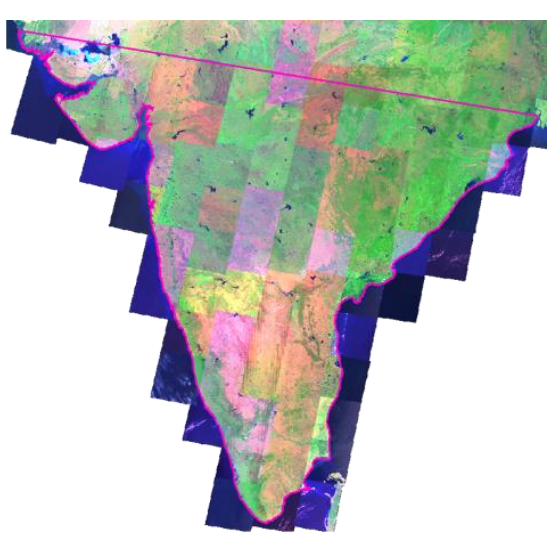

(c) 2005

Figure 2: The study region prepared from the satellite images for the year (a) 1975, (b) 1990, and (c) 2005. The bounded lines correspond to the total area considered in this study. 


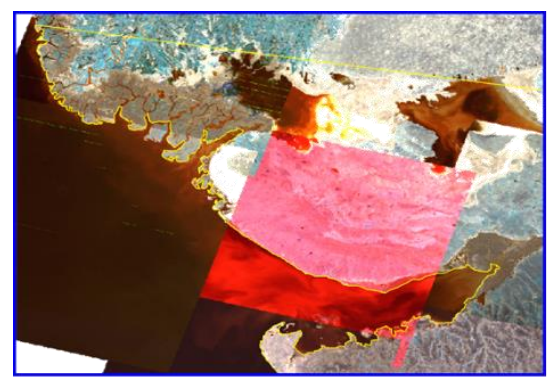

(a) 1975

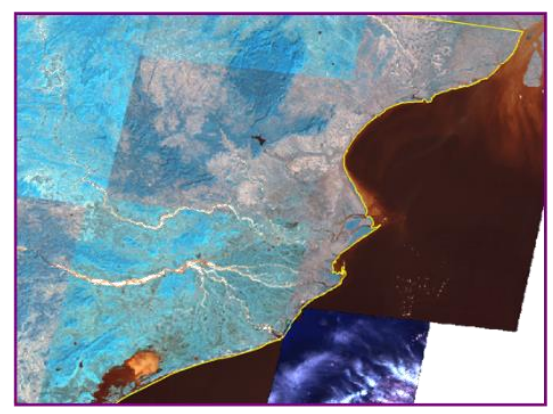

(d) 1975

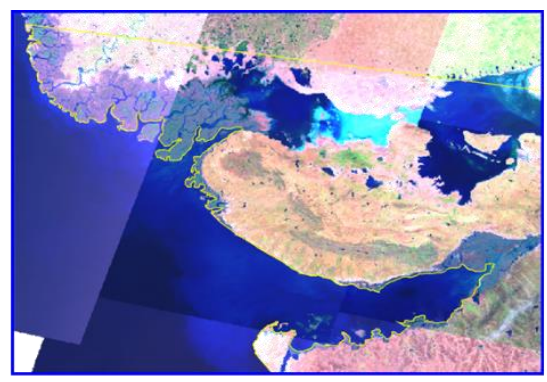

(b) 1990

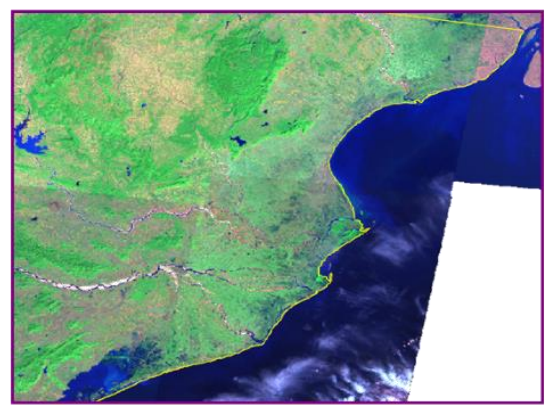

(e) 1990

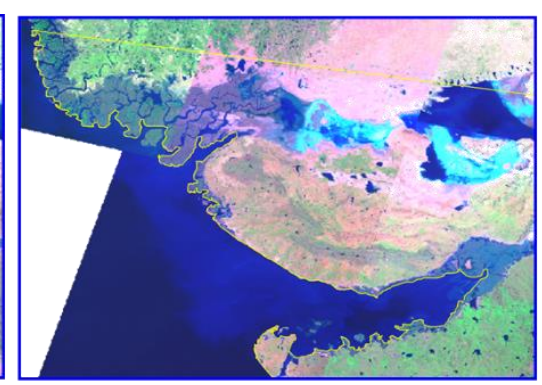

(c) 2005

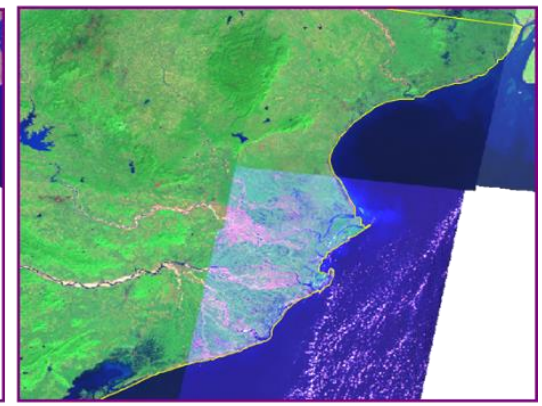

(f) 2005

Figure 3: Snapshots of two regions in three different years (a, d) 1975, (b, e) 1990, and (c, f) 2005.

Table 1: Area estimation of the landmass that bounded by the Indian coast in three different years.

\begin{tabular}{cc}
\hline Year & Area in sq. km \\
\hline 1975 & 1593923 \\
1990 & 1593997 \\
2005 & 1594053 \\
\hline
\end{tabular}

Although the sediment depositions along the Indian coast on satellite images were identified (as shown in Figure 3), but the quantitative estimation of sediment was not considered in the present study. Only the whole area of the landmass that bounded by the coast of India is estimated in this study from the Landsat datasets. The previous researches and our snapshots confirmed that the sediment deposits along the Indian coast for the years and years and causes expansion. Thus the overall expansion of the present study might be because of the same cause. According to 
Chandramohan et al. (2001), nearly $1.2 \times 10^{12}$ kilogram of sediments discharge annually in to the sea along the coast of India. Moreover, India lost $\sim 29 \%$ of its eroded soil permanently in to the sea (Narayanna and Babu, 1983). Manjunatha and Shankar (1992) also documented the sedimentation rates at 0.72 and $0.56 \mathrm{~mm} / \mathrm{yr}$ in 2 cores along the continental shelf of western India. All these lead to expansion in landmass. Many precious studies including the Indian coastal regions highlighted about the land use and land cover changes during this period (e.g., Nayak and Mandal, 2012, 2019b, 2019c; Nayak et al., 2021). Such changes in the land use and land cover change in the interior and/or the coast of the India could also be another reason to erode the land surface. Other reasons could be associated with natural hazards, climate change, and human activities. Natural hazards affect the environment to a great extent. When it occurs, it makes soil erosion volcanic eruption at some places and reduces the landscape by washing away the surface of the landscape. At the same time the washed surface matters deposits as the sediments either in river bank or in sea beaches resulting the landscape expansion. Climate change takes a vital role for reducing or expanding the landscape because the climate change alters the rainfall amount, temperature range, wind pattern, sensible/ latent heat fluxes etc. which in turn influence the underlying land surface process and thus the landscape. Human activities also play a major role for expanding or reducing the landscape. Degradation of landscape, deforestation, urbanization etc. are all due to the human activities. These activities modify the land surface process through change in albedo, runoff ratio, change in evapotranspiration, absorption of solar radiation and re-emission, photosynthetic ally active radiation etc. (Nayak et al., 2018) As a result, soil erosion occurs and surface of landscape escapes and the same are deposited somewhere else.

Our overall estimations are based on the preliminary analysis with very low resolution and high scale parameters. Thus these estimations may be associated with some errors because of the resolution and scale selected in this study. However, these results can be more accurately reproduced by reducing the scale and using further higher resolution images. Thus it is suggested to further investigate on the same issue with very high resolution datasets and extent the analysis to recent years.

\section{Concussions}

The inference that can be drawn from the results and discussions presented in the previous sections are as follows: 
The landmass that bounded by the Indian coast is expanding and it is assessed as $130 \mathrm{sq} \mathrm{km}$ during 1975-2005. This estimation is based on screen visual interpretation technique from the NASA Landsat imageries. The results indicate that the total landmass is expanded by $74 \mathrm{sq} . \mathrm{km}$ in first fifteen years and it is further expanded by 56 sq. $\mathrm{km}$ in next fifteen years. The overall analysis indicates that such expansion could be because of sediment deposition along the Indian coast during this period which mostly caused by the soil erosion and transforming them from the inland into the sea by rivers.

\section{Acknowledgements}

Authors thanks to Global Land Cover Facility (GLCF), for providing the NASA Landsat MSS, TM and $\mathrm{ETM}^{+}$data. Indian Institute of Technology Kharagpur is acknowledged for providing the required facilities for conducting this research work.

\section{References}

Angusamy, N., \& Rajamanickam, G. V. (2006). Depositional environment of sediments along the southern coast of Tamil Nadu, India. Oceanologia, 48(1).

Australia Network News., by Donald, P.M. Climate scientists find Pacific islands expanding, 3 June 2010.

BBC News Asia-Pacific., by Bryant, N. Low-lying Pacific islands 'growing not sinking', 3 June 2010.

Chandramohan, P., Jena, B. K., \& Kumar, V. S. (2001). Littoral drift sources and sinks along the Indian coast. Current Science, 292-297.

Jayappa, K. S., Kumar, G. V., \& Subrahmanya, K. R. (2003). Influence of coastal structures on the beaches of southern Karnataka, India. Journal of coastal research, 389-408.

Kunte, P. D., \& Wagle, B. G. (2005). The beach ridges of India: A review. Journal of Coastal Research, 174-183. 
Li, Z., Liu, W. Z., Zhang, X. C., \& Zheng, F. L. (2011). Assessing the site-specific impacts of climate change on hydrology, soil erosion and crop yields in the Loess Plateau of China. Climatic Change, 105(1), 223-242.

Manjunatha, B. R., \& Shankar, R. (1992). A note on the factors controlling the sedimentation rate along the western continental shelf of India. Marine Geology, 104(1-4), 219-224.

Mergner, H., \& Scheer, G. (1974). The physiographic zonation and the ecological conditions of some South Indian and Ceylon coral reefs. Proceedings of the Second International Coral Reef Symposium (Australia) 2: 3-30.

Mettier, R., Schlunegger, F., Schneider, H., Rieke-Zapp, D., \& Schwab, M. (2009). Relationships between landscape morphology, climate and surface erosion in northern Peru at $5 \mathrm{~S}$ latitude. International Journal of Earth Sciences, 98(8).

Narayana, D. V., \& Babu, R. (1983). Estimation of soil erosion in India. Journal of Irrigation and Drainage Engineering, 109(4), 419-434.

Nayak, S., \& Behera, M. D. (2008). Land use/land cover classification and mapping of Pilibhit District Uttar Pradesh India. The Indian Geographical Journal, 83(1), 15-24.

Nayak, S., \& Mandal, M. (2012). Impact of land-use and land-cover changes on temperature trends over Western India. Current science, 1166-1173.

Nayak, S., Mandal, M., Adhikari, A., \& Bhatla, R. (2013). Estimation of Indian coastal areas inundated into the sea due to sea-level rise during the 20th century. Current Science, 104(5), 583-585.

Nayak, S., Mandal, M., \& Maity, S. (2018). RegCM4 simulation with AVHRR land use data towards temperature and precipitation climatology over Indian region. Atmospheric Research, 214, 163-173. 
Nayak, S., \& Mandal, M. (2019a). Assessment of Sea Level and Morphological Changes along Indian Coastal Areas during 1975-2005. Earth Science India, 12(2), 117-125.

Nayak, S., \& Mandal, M. (2019b). Impact of land use and land cover changes on temperature trends over India. Land Use Policy, 89, 104238.

Nayak, S., \& Mandal, M. (2019c). Examining the impact of regional land use and land cover changes on temperature: the case of Eastern India. Spatial Information Research, 27(5), 601-611.

Nayak, S., Maity, S., Singh, K. S., Nayak, H. P., \& Dutta, S. (2021). Influence of the Changes in Land-Use and Land Cover on Temperature over Northern and North-Eastern India. Land, $10(1), 52$.

Thanh, T. D., Saito, Y., Van Huy, D., Nguyen, V. L., Ta, T. K. O., \& Tateishi, M. (2004). Regimes of human and climate impacts on coastal changes in Vietnam. Regional Environmental Change, 4(1), 49-62.

Webb, A. P., \& Kench, P. S. (2010). Vulnerability of atoll islands to sea level rise: multi-decadal analysis of island change in the central Pacific. Global and Planetary Change, 72, 234-246. 